\title{
Cognitive Improvement in Healthy Older Adults Can Parallel That of Younger Adults Following Lifestyle Modification: Support for Cognitive Reserve During Aging
}

\author{
Thomas B. Shea ${ }^{\mathrm{a}, *}$ and Ruth Remington ${ }^{\mathrm{b}}$ \\ ${ }^{a}$ Department of Biological Sciences, UMass Lowell, Lowell, MA, USA \\ ${ }^{\mathrm{b}}$ Department of Nursing, Framingham State University, Framingham, MA, USA
}

Accepted 18 June 2018

\begin{abstract}
Executive function was assayed following a nutritional supplementation in healthy adults using the Trail Making Test. Comparison with published normative scores demonstrated that cohorts from 35-74 years of age displayed similar relative improvement compared to their own baseline performance. These findings support early, pro-active lifestyle modifications to maintain cognitive performance during aging and further demonstrate the persistence of cognitive reserve in healthy older adults.
\end{abstract}

Keywords: Aging, cognitive performance, executive function, lifestyle modification, nutritional supplementation

Cognitive decline can accompany otherwise healthy aging. The degree of variance in cognitive performance among aging individuals, and moreover among cognitive domains in those individuals displaying decline, is consistent with compensatory mechanisms [1, 2]. Physical changes in neuronal circuitry accompany development, maturation, and senescence [3]. While cognitive decline is often associated with aging, functional decline in connectivity of large-scale brain networks are observed over the entire adult life span [4-6]. Some aspects of cognitive decline manifest as early as the second to third decade of life [7]. It therefore remains unclear whether or not cognitive performance declines throughout adult life, and reaches a threshold reflected by cognitive impairment during advanced age. This highlights the importance of preventative measures prior to

\footnotetext{
*Correspondence to: Thomas B. Shea, Department of Biological Sciences, UMass Lowell, Lowell, MA 02154, USA. Tel.: +1 978934 2881; Fax: +1 978934 3044; E-mail: thomas_Shea@uml. edu.
}

any detectable cognitive decline. Despite age-related decline in neural plasticity, considerable cognitive reserve persists during aging [8-12]. Lifestyle modifications including nutritional and social enrichments and cognitive exercise/training can enhance and preserve cognitive performance in older adults [13-21]. Moreover, multiple studies indicate that improved nutrition promotes and maintains cognitive performance throughout the entire life span including aged as well as young adults [20, 22-26]. Recent studies highlight that nutritional supplementation also maintains functional connectivity during aging [27].

Monitoring of executive function is particularly useful to assay cognitive performance [28]. The TrailMaking Test (TMT) is a well-recognized standard neuropsychological test of executive function useful not only for assessment of cognitive decline associated with progression of mild cognitive impairment (MCI) and dementia, but is also useful to monitor cognitive decline that may accompany otherwise healthy aging $[29,30]$. Participants in part A of this 
test (TMTA) are asked to connect a series of numbers (1-25) in order. This is immediately followed by part B (TMTB), in which participants are asked to connect a series of alternating numbers and letters in order (1,A,2,B,3,C,4,D, etc.). Tracking these alternating sequences in TMTB is particularly useful for examination of the influence of age on otherwise healthy cognitive performance, since slowing of "switching" of tasks has been observed in elderly versus younger adults [31]. The length of time for completion of each test is recorded, which allows monitoring of an individual's improvement or decline over time. In both cases, they coached through an untimed practice sample immediately prior to testing and their understanding of the task is ascertained prior to commencing. Performance on this test is subject to a variety of impairments and can detect difficulties in neuromuscular coordination and in following simple instructions (TMTA) to executive function (TMTB) [32]. Performance on the TMT is also subject to participant age and education. Slower TMT-B completion in older adults was positively correlated with thinning of frontal, temporal, and parietal cortex [33].

The usefulness of the TMT has been expanded by the compilation of normative scores encompassing a wide age range (18-79), as well as the education level of the participant [34]. Tombaugh [34] presents tabulated scores based upon a total of 911 community-dwelling individuals, which are classified by time of completion of TMTA and, separately, TMTB (Table 1). Age groups consist of either 5 or 10year spans. For individuals 55 years of age or older, education can influence executive function $[18,19]$ and exerts a positive influence on scoring in the TMT; Tombaugh [34] therefore presents two sets of normative scores for age groups $\geq 55$ years of age: those with $0-12$ years of education, and those with $12+$ years of education (Table 1). Table 1 presents a subset of the stratification relevant to our study. These normative scores allow comparison of performance among a diverse population and assist in characterizing the level of an individual's performance versus the anticipated performance for that individual's age and education level [29, 35]. Notably, Tombaugh [34] has been cited over 1,500 times [36].

Chan et al. tested the impact of lifestyle modification (via nutritional supplementation) on executive function in a cohort of adults of diverse ages that had no known nor suspected dementia; the details of the supplementation are well-described in prior reports and need not be reiterated herein [37]. As
Table 1

A subset of stratified scores for TMTB

\begin{tabular}{lc}
\hline Age/Education & Normative Scores on TMTB \\
\hline $18-24$ & $47.0 \pm 12.7$ \\
$25-34$ & $50.7 \pm 12.4$ \\
$35-44$ & $58.5 \pm 16.4$ \\
$45-54$ & $63.8 \pm 14.4$ \\
$55-59(12+)$ & $68.7 \pm 21.0$ \\
$60-64(12+)$ & $64.6 \pm 18.6$ \\
$65-69(12+)$ & $67.1 \pm 09.3$ \\
$70-74(12+)$ & $86.3 \pm 24.1$ \\
\hline
\end{tabular}

" $12+$ " is the designation that the particular cohort has completed 12 or more years of education; normative scores for cohorts of these ages with 0-12 years of age are not shown. Normative scores are reported as the mean \pm standard deviation in seconds. The age cohorts $25-34,35-44$, and $45-54$ did not display education-dependent differences. See Tombaugh [34] for more details.

described [38], participants consisted of both genders 18-86 years with no known or suspected cognitive difficulties. Executive function was monitored using the TMT prior to and following supplementation for 3 months [37,38]. Cohorts randomized to the formulation or placebo were statistically identical in age, gender, education, and baseline performance on the TMT. After 3 months, the cohort receiving the formulation had improved statistically compared to their own baseline performance and to that of the cohort receiving the placebo. An additional cohort receiving the formulation under open-label conditions displayed improvement statistically identical to that of the cohort receiving the formulation under blind conditions.

We considered that the diverse age range of participants in this study provided an opportunity to determine whether or not there were differential responses among younger versus older individuals. We therefore analyzed herein the performance on TMTB of different age groups of individuals receiving the formulation stratified according to Tombaugh as follows: $35-44,45-54,55-59,65-69$, and 70-74 years of age $[34,38]$. According to Tombaugh, the age groups 35-44 and 45-54 do not display educationdependent differences in the TMT, while those 65-69 and 70-74 do [34]. Since all but a few participants in Chan et al. had completed $12+$ years of education, those within in the age ranges of 55-59, 60-64, 65-69, and 70-74 are exclusively those with $12+$; individuals aged 35-44 and 45-54 were not stratified according to education level [34].

All age groups displayed improvement in TMTB over 3 months (Table 1). The standard deviations for the participants in Chan et al. (both before and after treatment), as well as those for the normative 
Table 2

Comparison of cohorts from Chan et al. [37] with normative data stratified according to age and education level according to Tombaugh [34]

\begin{tabular}{lccccccc}
\hline $\begin{array}{l}\text { Participant } \\
\text { Age Group }\end{array}$ & $\begin{array}{c}\text { Number of } \\
\text { Participants }\end{array}$ & $\begin{array}{c}\text { Years of } \\
\text { Education }\end{array}$ & $\begin{array}{c}\text { Baseline } \\
\text { Scores }\end{array}$ & $\begin{array}{c}\text { Norm. } \\
\text { Scores }\end{array}$ & $\begin{array}{c}\text { Score of Chan et al. } \\
\text { cohorts after } \\
\text { treatment }\end{array}$ & $\begin{array}{c}\text { Change in Score } \\
\text { for Chan et al. } \\
\text { cohorts }\end{array}$ & $\begin{array}{c}\text { Average } \\
\text { improvement in } \\
\text { performance }\end{array}$ \\
\hline $35-44$ & 5 & $\mathrm{n} / \mathrm{a}$ & $61.2(19.4)$ & $58.5(16.4)$ & $46(9.2)$ & -15.2 & $15 \%$ \\
$45-54$ & 14 & $\mathrm{n} / \mathrm{a}$ & $56(13)$ & $63.8(14)$ & $44.6(12)$ & -11.4 & $20 \%$ \\
$55-59$ & 9 & $12+$ & $61.8(13.8)$ & $68.7(21.0)$ & $58.1(12.6)$ & -4.7 & $5.9 \%$ \\
$60-64$ & 16 & $12+$ & $68.5(24)$ & $64.6(18.6)$ & $56.9(16.5)$ & -11.6 & $16.9 \%$ \\
$65-69$ & 9 & $12+$ & $74.3(31)$ & $67.1(9)$ & $61.8(21)$ & -12.6 & $16 \%$ \\
$70-74$ & 11 & $12+$ & $104.7(58.5)$ & $86.3(24)$ & $81.82(32.6)$ & -22.9 & $21.9 \%$ \\
\hline
\end{tabular}

Values for scores are the mean in seconds, with standard deviation in parenthesis.

scores provided by Tombaugh et al., are large, which precludes definitive comparisons [34, 37]. However, the extent of improvement for most cohorts of Chan et al. resulted in averages scores that corresponding to younger normative age groups. For example, the mean baseline score for the cohort from 35-44 years of age initially fell within the anticipated normative range according to Tombaugh et al. However, following treatment, this cohort displayed a mean baseline that instead corresponded to the normative range of 18-24 years of age. Similar shifts in mean scores were observed for cohorts of Chan et al. that were 55-59, 60-64, and 65-69 years of age. Baseline mean performance of the cohort 70-74 years of age was substantially worse than the mean anticipated normative score, although their performance was within the normative standard deviation; however, their extent of improvement $(21.9 \%)$ not only matched or exceeded that of all other cohorts, but also brought them within their anticipated normative score. By contrast, the cohort from 55-59 years of age displayed a relatively small reduction as compared to other cohorts. However, it should be noted this cohort was already performing approximately $10 \%$ better at baseline than anticipated according to normative scores. Of note, the average normative score for the 50-59 year age group was higher than that for both the 60-64 and 65-69 year age groups; the significance of differential performance of this cohort is unclear (Table 1) [34].

The nature and extent of cognitive decline including executive function can vary [39]. Monitoring of executive function is particularly useful to track progression from normal aging to MCI and Alzheimer's disease [28]. However, even in the absence of dementia, cognitive decline, and in particular a decline in executive function, profoundly impacts quality of life, since it can lead to impaired decision making, including those affecting health and financial wellbeing [40-42].
While multiple studies indicate that improved nutrition promotes and maintains cognitive performance throughout the entire life span, most studies include a relatively narrow age range of participants [20, 22-26]. Studies of healthy adults may include individuals with unrecognized early-stage dementia; such individuals may not display any impairment in daily cognitive and/or behavioral function but may nevertheless perform worse than anticipated for their age in executive function tasks [43]. Several such individuals were identified among those selfreporting no cognitive difficulties among the aged cohort of Chan et al. [37] and the scores of these individuals were excluded from further analyses as described [38]. Herein, the aged cohort (70-74 years of age) improved to the same or even greater extent than did all younger cohorts, despite that the aged cohort had the slowest baseline scores; this finding supports the notion of cognitive reserve. The inclusion of diverse ages of participants within Chan et al. [37] provides direct support that improvement in executive function can occur across the adult life span following a nutritional intervention and that older adults can display an extent of improvement that parallels that of younger adults. Notably, while the performance of a total of 64 individuals were examined, once separated into cohorts according to Tombaugh [34], the number of individuals in each age group was relatively small; a larger study is therefore warranted. Nevertheless, these findings underscore the potential of early intervention to enhance the retention of cognitive reserve in older adults.

\section{ACKNOWLEDGMENTS}

Dr. Shea is a non-salaried advisor for Sevo Nutraceuticals (Waltham, MA), which licensed the formulation utilized in references [37, 38]. Both Dr. Shea and UMass Lowell have a financial interest in this company and the formulation. 


\section{REFERENCES}

[1] Nyberg L, Lovden M, Riklund K, Lindenberger U, Backman L (2012) Memory, aging and brain maintenance. Trends Cog Sci 16, 292-305.

[2] Buckner RL (2004) Memory and executive function review in aging and AD: Multiple factors that cause decline and reserve factors that compensate. Neuron 44, 195-208.

[3] Shing YL, Werkle-Bergner M, Brehmer Y, Muller V, Li S-C, Lindenberger U (2010) Episodic memory across the lifespan: The contributions of associative and strategic components Neurosci Biobehav Rev 34, 1080-1091.

[4] Zhang HY, Chen WX, Jiao Y, Xu Y, Zhang XR, Wu JT (2014) Selective vulnerability related to aging in large-scale resting brain networks. PLoS One $\mathbf{9}$, e108807.

[5] Archer JA, Lee A, Qiu A, Chen SH (2016) A comprehensive analysis of connectivity and aging over the adult life span. Brain Connect 6, 169-185.

[6] La Corte V, Sperduti M, Malherbe C, Vialatte F, Lion S, Gallarda T, Oppenheim C, Piolino P (2016) Cognitive decline and reorganization of functional connectivity in healthy aging: The pivotal role of the salience network in the prediction of age and cognitive performances. Front Aging Neurosci 8, 204.

[7] Salthouse TA (2009) When does age-related cognitive decline begin? Neurobiol Aging 30, 507-514.

[8] Hertzog C, Kramer AF, Wilson RS, Lindenberger U (2008) Enrichment effects on adult cognitive development: Can the functional capacity of older adults be preserved and enhanced? Psychol Sci Public Interest 9, 1-65.

[9] Mahncke HW, Bronstone A, Merzenich MM (2006) Brain plasticity and functional losses in the aged: Scientific bases for a novel intervention. Prog Brain Res 157, 81-109.

[10] Jones S, Nyberg L, Sandblom J, Stigsdotter Neely A, Ingvar M, Magnus Petersson K, Bäckman L (2006) Cognitive and neural plasticity in aging: General and task-specific limitations. Neurosci Biobehav Rev 30, 864-871.

[11] Greenwood PM (2007) Functional plasticity in cognitive aging: Review and hypothesis. Neuropsychology 21, 657673.

[12] Stern Y (2012) Cognitive reserve in ageing and Alzheimer's disease. Lancet 11, 1006-1012.

[13] Noack H, Lövdén M, Schmiedek F, Lindenberger U (2009) Cognitive plasticity in adulthood and old age: Gauging the generality of cognitive intervention effects. Restor Neurol Neurosci 27, 435-453.

[14] Borella E, Carbone E, Pastore M, De Beni R, Carretti B (2017) Working memory training for healthy older adults: The role of individual characteristics in explaining shortand long-term gains. Front Hum Neurosci 11, 99.

[15] Buitenweg JIV, van de Ven RM, Prinssen S, Murre JMJ, Ridderinkhof KR (2017) Cognitive flexibility training: A large-scale multimodal adaptive active-control intervention study in healthy older adults. Front Hum Neurosci 11, 529.

[16] Martin M, Clare L, Altgassen AM, Cameron MH, Zehnder F (2011) Cognition-based interventions for healthy older people and people with mild cognitive impairment. Cochrane Database Syst Rev 1, CD006220.

[17] Kelly ME, Duff H, Kelly S, McHugh Power JE, Brennan S, Lawlor BA, Loughrey DG (2017) The impact of social activities, social networks, social support and social relationships on the cognitive functioning of healthy older adults: A systematic review. Syst Rev 6, 259.

[18] Brewster PW, Melrose RJ, Marquine MJ, Johnson JK, Napoles A, MacKay-Brandt A, Farias S, Reed B, Mungas
D (2014) Life experience and demographic influences on cognitive function in older adults. Neuropsychology 28, 846858 .

[19] Gross AL, Mungas DM, Crane PK, Gibbons LE, MacKayBrandt A, Manly JJ, Mukherjee S, Romero H, Sachs B, Thomas M, Potter GG, Jones RN (2015) Effects of education and race on cognitive decline: An integrative study of generalizability versus study-specific results. Psychol Aging 30, 863-880.

[20] Shea TB, Remington R (2015) Nutritional supplementation for Alzheimer's disease. Curr Opin Psychiatry 28, 141-147.

[21] Caselli RJ, Beach TG, Knopman DS, Graff-Radford NR (2017) Alzheimer disease: Scientific breakthroughs and translational challenges. Mayo Clin Proc 92, 978-994.

[22] Dauncey MJ (2014) Nutrition, the brain and cognitive decline: Insights from epigenetics. Eur J Clin Nutr 68, 11791185.

[23] Fiorentino M, Perignon M, Kuong K, de Groot R, Parker M, Burja K, Dijkhuizen MA, Sokhom S, Chamnan C, Berger J, Wieringa FT (2018) Effect of multi-micronutrientfortified rice on cognitive performance depends on premix composition and cognitive function tested: Results of an effectiveness study in Cambodian schoolchildren. Public Health Nutr 21, 816-827.

[24] van de Rest O, Berendsen AA, Haveman-Nies A, de Groot LC (2015) Dietary patterns, cognitive decline, and dementia: A systematic review. Adv Nutr 6, 154-168.

[25] Morris MC, Tangney CC, Wang Y, Sacks FM, Barnes LL, Bennett DA, Aggarwal NT (2015) MIND diet slows cognitive decline with aging. Alzheimers Dement 11, 1015-1022.

[26] Meeusen R, Decroix L (2018) Nutritional supplements and the brain. Int J Sport Nutr Exerc Metab 28, 200-211.

[27] Jannusch K, Jockwitz C, Bidmon HJ, Moebus S, Amunts K, Caspers S (2017) A Complex interplay of vitamin B1 and B6 metabolism with cognition, brain structure, and functional connectivity in older adults. Front Neurosci 11, 596.

[28] Kirova AM, Bays RB, Lagalwar S (2015) Working memory and executive function decline across normal aging, mild cognitive impairment, and Alzheimer's disease. Biomed Res Int 2015, 748212

[29] Connor KO, Chaisson C, Green RC, Stern RA (2008) Trail Making Test errors in normal aging, mild cognitive impairment, and dementia. Arch Clin Neurophsychol 23, 129-137.

[30] Teng E, Lu PH, Cummings JL (2007) Neuropsychiatric symptoms are associated with progression from mild cognitive impairment to Alzheimer's disease. Dement Geriatr Cogn Disord 24, 253-259.

[31] Cepeda NJ, Kramer, AF, Gonzalez de Sather JC (2001) Changes in executive control across the life span: Examination of task-switching performance. Dev Psychol 37, 715-730.

[32] Bowie CR, Harvey PD (2006) Administration and interpretation of the Trail Making Test. Nat Protoc 1, 2277-2281.

[33] MacPherson SE, Cox SR, Dickie DA, Karama S, Starr JM, Evans AC, Bastin ME, Deary IJ (2017) Processing speed and the relationship between Trail Making Test-B performance, cortical thinning and white matter microstructure in older adults. Cortex 95, 92-103.

[34] Tombaugh TN (2004) Trail Making Test A and B: Normative data stratified by age and education Arch Clin Neuropsychol 19, 203-214.

[35] Perianez JA, Rios-Lago M, Rodriguez-Sanchez JM, Adrover-Roig D, Roig Sanchez-Cubillo I, Crespo-Facorro, B, Quemada JI, Facelo F (2007) Trail Making Test in traumatic brain injury, schizophrenia, and normal ageing: 
Sample comparisons and normative data. Arch Clin Neuropsychol 22, 433-447.

[36] Google Scholar: https://scholar.google.com/scholar?\&q= tombaugh+trail+making+test

[37] Chan A, Lepore A, Kotoya E, Zemianek J, Remington R, Shea TB (2010) Efficacy of a vitamin/nutriceutical formulation on cognitive speed and recall in adults with no known or suspected dementia. J Nutr Health Aging 14, 224-230.

[38] Shea TB, Remington R (2018) Apparent cognitive decline as revealed by an executive function test within a cohort of elderly individuals self-reporting normal cognitive performance. J Alzheimers Dis 61, 913-915.

[39] Mungas D, Beckett L, Harvey D, Farias ST, Reed B, Carmichael O, Olichney J, Miller J, DeCarli C (2010) Heterogeneity of cognitive trajectories in diverse older persons. Psychol Aging 25, 606-619.
[40] James BD, Boyle PA, Yu L, Han SD, Bennett DA (2015) Cognitive decline is associated with risk aversion and temporal discounting in older adults without dementia. PLoS One 10, e0121900.

[41] Boyle PA, Yu L, Wilson RS, Gamble K, Buchman AS, Bennett DA (2012) Poor decision making is a consequence of cognitive decline among older persons without Alzheimer's disease or mild cognitive impairment. PLoS One 7, e43647.

[42] Boyle PA, Yu L, Wilson RS, Segawa E, Buchman AS, Bennett DA (2013) Cognitive decline impairs financial and health literacy among community-based older persons without dementia. Psychol Aging 28, 614-624.

[43] Morris JC, Price JL (2001) Pathologic correlates of nondemented aging, mild cognitive impairment, and early-stage Alzheimer's disease. J Mol Neurosci 17, 101-117. 